IZA DP No. 7767

Career Lesbians: Getting Hired for Not Having Kids?

Stijn Baert

November 2013 


\title{
Career Lesbians: Getting Hired for Not Having Kids?
}

\author{
Stijn Baert \\ Sherppa, Ghent University \\ and IZA
}

Discussion Paper No. 7767

November 2013

\author{
IZA \\ P.O. Box 7240 \\ 53072 Bonn \\ Germany \\ Phone: +49-228-3894-0 \\ Fax: +49-228-3894-180 \\ E-mail: iza@iza.org
}

\begin{abstract}
Any opinions expressed here are those of the author(s) and not those of IZA. Research published in this series may include views on policy, but the institute itself takes no institutional policy positions. The IZA research network is committed to the IZA Guiding Principles of Research Integrity.

The Institute for the Study of Labor (IZA) in Bonn is a local and virtual international research center and a place of communication between science, politics and business. IZA is an independent nonprofit organization supported by Deutsche Post Foundation. The center is associated with the University of Bonn and offers a stimulating research environment through its international network, workshops and conferences, data service, project support, research visits and doctoral program. IZA engages in (i) original and internationally competitive research in all fields of labor economics, (ii) development of policy concepts, and (iii) dissemination of research results and concepts to the interested public.
\end{abstract}

IZA Discussion Papers often represent preliminary work and are circulated to encourage discussion. Citation of such a paper should account for its provisional character. A revised version may be available directly from the author. 
IZA Discussion Paper No. 7767

November 2013

\section{ABSTRACT \\ Career Lesbians: Getting Hired for Not Having Kids?}

Using a field experiment, we investigate whether discrimination based on women's sexual orientation differs by age and family constraints. We find weakly significant evidence of discrimination against young heterosexual women. This effect is driven by age (and fertility) rather than by motherhood. We do not find any unequal treatment at older ages. This age effect is consistent with our theoretical expectation that, relative to lesbian women, young heterosexual women are penalised for getting children more frequently and taking on, on average, more at-home-caring tasks.

\section{NON-TECHNICAL SUMMARY}

Former contributions to the academic literature have shown that homosexual women are anno 2013 still discriminated against in the labour market in European countries such as Austria and Greece. We contribute to this literature by sending out fictitious job applications to real vacancies in Belgium, a country that has had an openly homosexual Prime Minister since December 2011, and that was in 2003 the second country in the world to legalise same-sex marriage. Our results show that in general heterosexual and homosexual women are treated equally in the Belgian (Flemish) labour market. Moreover, young homosexual women get even more positive callback than their heterosexual counterparts. This age effect is consistent with our theoretical expectation that, relative to lesbian women, young heterosexual women are penalised for getting children more frequently and taking on, on average, more at-home-caring tasks.

JEL Classification: $\quad \mathrm{C} 93, \mathrm{~J} 13, \mathrm{~J} 16, \mathrm{~J} 71$

Keywords: labour market discrimination, sexual orientation, motherhood

Corresponding author:

Stijn Baert

Faculty of Economics and Business Administration

Sherppa, Ghent University

Tweekerkenstraat 2

B-9000 Ghent

Belgium

E-mail: Stijn.Baert@UGent.be 


\section{Introduction}

In the last decade, several economic studies tested discrimination based on women's sexual orientation. Using comprehensive field experiments, Drydakis (2011, Forthcoming), Weichselbaumer (2003, 2013), Ahmed et al. (2011a) and Patacchini et al. (2012) identified high levels of discrimination against lesbians in Greece and Cyprus, moderate levels in Austria and Germany, low levels in Sweden and no unequal treatment at all in Italy. This evidence of discrimination is worrisome. Not only is discrimination unacceptable from an ethical perspective, but it also has important economic consequences (Drydakis, 2011).

As argued by Neumark (1999), it is important from a policy perspective to determine the nature of discrimination in order to design adequate policy actions. In the context of discrimination based on sexual orientation, several mechanisms have been proposed in the theoretical literature. These mechanisms can be grouped under the well-known models of taste discrimination (Becker 1957) and statistical discrimination (Arrow 1971).

On the one hand, there are valid theoretical arguments for taste-based discrimination. Analogous to the general case, taste discrimination against lesbians could be caused by the general distaste that employers, employees and customers may have for sexual minorities and the experienced disutility of interacting with them. As a consequence, employers may be prepared to hire heterosexual candidates even if they are of lower productivity or have higher reservation wages.

On the other hand, there are also reasons to expect statistical discrimination in favour of 
lesbian workers. Statistical discrimination occurs when employers examine statistics about a group's average performance to predict a particular applicant's productivity. Several factors may lead employers to expect higher average productivity from lesbians relative to straight women. First, lesbians are documented as being, on average, more "masculine", that is, more dominant, autonomous and assertive. This characteristic may match well with some specific jobs and adhere to the ideal of masculinity that is associated with labour market success (Clain and Leppel 2001; Berg and Lien 2002; Blandford 2003). ${ }^{1}$ Second, lesbians are documented as having on average, a more committed and continuous labour market participation. This characteristic results from two different factors. On the one hand, on average, lesbians have children less frequently than heterosexual women and, due to a less traditional division of labour within the household, lesbians on average engage in less rearing tasks, which are conditional on having children in the first place, than heterosexual women do. On the other hand, this less traditional division of labour also results in the reduction of other household responsibilities. Due to these characteristics, lesbians may be more productive and accumulate more human capital as the return on market-oriented human capital investments will be higher among them (Weichselbaumer 2003; Elmslie and Tebaldi 2007; Ahmed et al. 2011b; Antecol and Steinberger 2011; Drydakis 2011). To date, however, empirical studies have not been designed to test the empirical importance of these theoretical channels. ${ }^{2}$

\footnotetext{
${ }^{1}$ Mention that behaving in more manly ways may at the same time underlie taste discrimination.

${ }^{2}$ In a recent correspondence test, Drydakis (Forthcoming) attempts to investigate the relative share of taste versus statistical discrimination (without focussing on the underlying theoretical channels) by varying the amount of information
} 
We are the first to investigate whether unequal treatment of heterosexual and lesbian job candidates differs by age and motherhood. ${ }^{3}$ To this end, we conducted a field experiment in the Belgian (Flemish) labour market. We sent out pairs of fictitious female job applications to real job openings. Within each pair, the candidates' characteristics were similar except for sexual orientation. We compare the subsequent call-back from employers for candidates aged 25 versus 37 and for candidates indicating one child versus no children. If the aforementioned theoretical mechanisms related to getting and rearing children are important in favour of lesbians, it should lead to better relative hiring chances for lesbians when the candidates reveal their young age (for that is when the probability of maternity is high) and motherhood (compared to their relative hiring chances at older ages and when indicating no children).

Readers may take an interest in this study for a number of additional reasons. First, as lesbians hold the middle ground between heterosexual women and men in the obstacles they face in the labour market related to getting and rearing children, our study also contributes to the literature on (the experimental identification of) gender discrimination in general (Neumark et al. 1996; Goldin and Rouse 2000; Weichselbaumer 2004; Riach and

included in the job application. As the information premium for sexual orientation minorities does not reduce the discriminatory patterns, he concludes that discrimination against lesbian women is a matter of distaste and not of uncertainty.

${ }^{3}$ Simultaneously with our field experiment, Weichselbaumer (2013) gathered experimental data in Germany. By varying the marital status of the fictitious job candidates, her study aims at testing whether employers interpret registered partnership among sexual minorities as a disciplining device that pushes them into normalised lifestyles. She finds that unequal treatment is quite homogeneous along this aspect. 
Rich 2006; Albert et al. 2011) and penalisation of women for having and rearing children in particular (Theunissen et al. 2009). In this respect, our results complement those of Petit (2007), who uses a methodology that is very similar to ours to study the effects of age and family constraints on gender discrimination in France. Referring to statistical discrimination due to the high probability of female career interruption as a principal explanation, she provides evidence for hiring discrimination against young women but no unequal treatment at all at older ages.

Second, we investigate unequal treatment in different occupations that potentially demonstrate a variation in discriminatory behaviour. Therefore, in our experiment, we include both typically female- and male-dominated jobs. We also differentiate between jobs in which personal contact with customers is important and jobs in which it is not important. To the best of our knowledge, we are the first to investigate customer driven sexual orientation discrimination.

Third, this is the first field experimental study of sexual orientation discrimination in Belgium. Belgium presents an interesting case, as its score on the ILGA-Europe Rainbow Map, which reflects the national legal and policy human rights situation of lesbian, gay, bisexual, transsexual and intersex people in Europe, that is higher than all the other countries in which field experimental studies of discrimination based on sexual orientation have been conducted before (ILGA-Europe 2013). This score is consistent with the liberal and tolerant public opinion towards sexual minorities in Belgium, as reflected in Eurobarometer (2006). Belgium has had an openly homosexual Prime Minister since December 2011, and in 2003, it was the second country in the world to legalise same-sex 
marriage. We use the latter feature to reveal the lesbian sexual orientation in our fictitious job applications in a direct and natural way by indicating the name of the applicant's spouse together with her marital status, thereby overcoming a major concern with previous correspondence studies that revealed lesbian sexual orientation by indicating involvement with a rainbow organisation. This concern is that the lesbian applicant's involvement may potentially conflate activism or radicalism with sexual orientation.

This article is structured as follows. In the next section, we outline our experimental research design. Subsequently, in Section 3, we present and discuss the statistical examination of the resulting dataset. A final section concludes the article.

\section{Methodology}

\subsection{Measuring Unequal Treatment by a Field Experiment}

Most studies of discrimination against (or in favour of) lesbians are based on nonexperimental data. These non-experimental studies focus mainly on earnings ${ }^{4}$ or employment ${ }^{5}$ differentials by sexual orientation based on survey or administrative data. In

\footnotetext{
${ }^{4}$ See Badgett (2006) for a review of early studies and see Black et al. (2003), Blandford (2003), Plug and Berkhout
} (2004), Arabsheibani et al. (2005), Carpenter (2005), Baumle (2009), Jepsen (2009) and Ahmed et al. (2011b) for more recent studies.

${ }^{5}$ See Leppel (2009). 
general, they suffer from two important statistical problems: unobserved heterogeneity and sample selection bias. First, job candidates who appear similar to researchers based on standard non-experimental data may look very different to employers. No conclusive proof of discrimination can be provided, as researchers cannot control all relevant variables taken into account by employers in making their hiring, remuneration and promotion decisions. Second, it is possible that individuals with better economic outcomes - who may be more confident in their interaction both with interviewers and colleagues - are more willing to disclose their lesbian orientation. This leads to an upwards bias of the measured outcomes of lesbians. In addition, the studies focussing on wage differentials may suffer from the nonrandom selection into employment of heterosexual and lesbian job applicants. Wage regressions may understate the full effects of discrimination based on sexual orientation by leaving out the fact that many applicants are barred from even earning a wage (Weichselbaumer 2003; Drydakis 2011).

To overcome the stated methodological problems, this study gathers data through an experimental approach. Specifically, we follow the studies described in the beginning of our introduction by relying on a correspondence test. Correspondence experiments to test for hiring discrimination on grounds such as ethnicity and beauty have been extensively used and refined during the last century (Bertrand and Mullainathan 2004; Rooth 2009). In these field experiments, pairs of fictitious written job applications are sent to real job openings. The two applications within each pair are similar except for the single characteristic that is to be tested. Unequal treatment based on this characteristic can be identified by monitoring the subsequent call-back. 
These field experiments have been widely viewed as providing the most convincing evidence of unequal treatment in hiring decisions (Riach and Rich 2002). A correspondence test eliminates selection on the basis of individual unobservable characteristics because all the information the employer receives is controlled by the researcher. Thus, strict equivalence between fictitious applicants is ensured and employer discrimination is disentangled from alternative explanations of differential hiring rates such as differential employee preferences and network effects.

\subsection{Construction of Fictitious Applications}

We generated pairs of template résumés and cover letters for 12 profiles of female job candidates. We call the members of these pairs "Type A" and "Type B" template applications. This allowed us to send two applications, one of each type, alternately assigned to the lesbian sexual orientation (see Section 2.3), to the same vacancy. To maximise comparability, both application types were identical in all job-relevant characteristics. The applications just differed in inessential details, such as the name of her alma mater, favourite sports and other particular personal details as well as in fonts and layout used in her application.

Six profiles featured women 25 years of age and six profiles featured women 37 years of age. We chose these particular ages by analogy with Petit's (2007) study. Statistics from the Flemish Agency for Care and Health show that in Flanders, the Northern, Dutch-speaking part of Belgium where we gathered our experimental data, the age-specific fertility rate 
peaks at the age of 29 . Therefore, the probability of (near-)future maternity is high at the age 25 . The choice of job candidates aged 37 results in a trade-off. On the one hand, the older a female job candidate is, the lower her probability of taking maternity leave. On the other hand, because in Belgium, older candidates have smaller chances of getting a job, adopting candidates older than 37 in our experiment could reduce the call-back probability substantially. The six profiles per age category allowed us to apply for vacancies with different requirements in both educational level and specialisation. We used three (middle)low-educated profiles with a secondary education degree $\left(\right.$ ISCED $\left.^{6} 3\right)$ in commerce, nursing and mechanical maintenance and three (middle-)high-educated profiles with a Bachelor's degree in office management, ergotherapy and engineering (ISCED 5).

Furthermore, all of the profiles were of married females of Belgian nationality. Their residences were located in one of the suburbs of Ghent, the second largest city of Flanders. The low-educated candidates graduated from a school with a good (and comparable) reputation at the age of 18 , whereas the high-educated candidates graduated at the age of 21 (office managers and ergotherapists) or 22 (engineers). None of the candidates experienced grade retention. The 25-year-old candidates within each pair acquired experience from one comparable job and did not experience spells of unemployment prior to sending out their résumés. The 37-year-old candidates acquired experience from two comparable positions and, like their younger counterparts, did not experience any spells of unemployment. In addition, we added the following features to each application: Dutch as a

\footnotetext{
${ }^{6}$ ISCED stands for International Standard Classification of Education.
} 
mother tongue, adequate French and English language skills, driver's license, computer skills and student employment experience. Moreover, the cover letters signalled a motivated, structured and capable person. We also included sport club memberships and student leadership positions for the high-educated candidates. Lastly, we added a fictitious postal addresses (based on real streets in middle-class neighbourhoods) and dates of birth to the applications. The template Type A and Type B résumés and cover letters are available upon request.

\subsection{Revelation of Sexual Orientation}

As stated above, we sent two applications, one Type A and one Type B, to each selected vacancy. We indicated marital status and the spouse's name for one member within each pair ("Married to Julie Van Damme" for the low-educated ones and "Married to Tineke De Letter" for the high-educated ones). ${ }^{7}$ The second member's resume made only mention of marital status ("Married") but did not indicate a partner's name. Our approach contrasts with all the aforementioned studies, whose subjects signal their lesbian sexual orientation by highlighting involvement with a federation for lesbian, gay, bisexual and transgender rights thereby contrasting themselves from heterosexual candidates who instead describe involvement in another organisation (such as an environmental union, a cultural centre or a

\footnotetext{
${ }^{7}$ Several human resource managers confirmed that including one's partner's name in the résumé together with the marital status is not uncommon in Belgium.
} 
humanitarian movement). ${ }^{8}$ The approach of those studies has two important limitations. First, sexual orientation is not indicated directly: heterosexual individuals may sympathise with sexual minorities and therefore be a member of (or work for) a rainbow organisation. Second, researchers acknowledge that a major concern with this approach is that the lesbian applicant's involvement may potentially conflate activism or radicalism with sexual orientation (Ahmed et al. 2011a; Drydakis 2011; Weichselbaumer 2013). As this activism could have a negative impact while the generosity signalled by the heterosexual candidate's engagement could have a positive impact on the employer's perception of the candidates, discrimination found by comparing their call-back runs the risk of being overestimated.

To eliminate any possible effect, the application type could have on call-backs, we alternated assignments of heterosexual and lesbian identity in the Type A and Type B applications. Moreover, we alternated the use of pairs of candidates aged 25 and 37 . In addition, both pair members indicated they had one son half of the time. Subsequently, we sent the resulting combinations in an alternating order to the employers, with approximately 24 hours in between each time.

${ }^{8}$ In addition, Ahmed et al. (2011a) mention in the application letter that the lesbian candidates "enjoy spending their spare time with their wife". In Weichselbaumer (2013), two signals for sexual orientation are used alternately: mentioning the involvement with a lesbian and gay organisation and mentioning a registered partnership with a person of the same gender. 


\subsection{Selection of Vacancies}

Between October 2012 and March 2013, we randomly selected 576 vacancies from the database of the Public Employment Service of Flanders (PES), the major job search channel in Flanders, for which our fictitious job candidates were adequately educated and experienced. These 576 vacancies were spread equally across six occupations differing by required skill-level, gender dominance and customer contact: (i) secretary (low-skilled, female-dominated, low level of customer contact), (ii) nanny (low-skilled, femaledominated, high level of customer contact), (iii) manual worker (low-skilled, maledominated, low level of customer contact), (iv) management assistant (high-skilled, femaledominated, low level of customer contact), (v) ergotherapist (high-skilled, femaledominated, high level of customer contact) and (iv) engineer (high-skilled, male-dominated, low level of customer contact). ${ }^{9}$

Including several occupations rather than just one is important to avoid the danger inherent in many of the aforementioned correspondence tests of a researcher simply picking an occupation with a high rate of discrimination. Furthermore, by doing this, we are able to contribute to the empirical literature on (sexual orientation) discrimination beyond our primary research focus. First, we are able to investigate whether the general theoretical and empirical evidence for a negative relationship between unequal treatment in hiring and the level of education of the candidate holds in the context of discrimination based on

\footnotetext{
${ }^{9}$ In the mentioned occupations dominated by females (males), at least $80 \%$ of the employees were of the female (male) gender in 2010 (source: Directorate-general Statistics and Economic Information Belgium).
} 
sexual orientation. ${ }^{10}$ Second, our results provide additional empirical evidence concerning the theoretical suggestion that discrimination against lesbians is less severe in maledominated occupations (Reiss et al. 1976). As discussed in the introduction, this suggestion is related to the perception of lesbians as being more masculine and behaving in more "manly" ways. It was previously tested by Ahmed et al. (2011a) and Drydakis (2011). Although the former study indeed reports that discrimination against lesbians apparent in Sweden only in typically female-dominated occupations, the latter study finds no substantial heterogeneity along this dimension. Third, it is a conscious choice to study both occupations with and without customer contact to test whether customer discrimination, as predicted by Becker's (1957) model of discrimination, is apparent in the context of discrimination based on sexual orientation.

\subsection{Measurement of Call-back}

All applications were sent to the employer by email. ${ }^{11}$ To avoid detection, we applied to no

${ }^{10}$ See for theoretical evidence Taubman and Wales (1974) arguing that higher education can act as a prejudices reducing screening device. See Bursell (2007), Carlsson and Rooth (2007) and Baert et al. (2013) for recent empirical evidence.

${ }^{11}$ We chose "Tania Pauwels" and "Ann D'hooghe" as the names of the low- and high-educated candidate, respectively, with the heterosexual identity and "Sofie Mertens" and "Elke Maes" as the names of the low- and higheducated candidate with the lesbian identity. We checked that these names did not represent a difference in socioeconomic background based on a study linking the (suffix of the) name Dutch speaking parents choose for their children with their (own) wage (Jobat, 2013). 
more than one vacancy with the same employer. Call-backs were received by telephone voicemail or email. The content of the responses is available upon request. Because we included postal addresses with a non-existent street number in the applications, we could not measure call-back by regular mail. However, several human resource managers confirmed that currently, employers rarely, if ever, invite job candidates for selection interviews by regular mail. To minimise inconvenience to the employers, we immediately declined invitations to job interviews. We designed the study so that all call-backs received later than 30 days after sending out the application were to be discounted (however, this turned out to be an unnecessary restriction because we hardly received any positive callbacks after 30 days). We define positive call-back as the situation in which the applicant is invited for an interview for the job for which she applied.

\subsection{Research Limitations}

Before reporting and discussing the results of our research, we indicate three limitations in our research design. For an in-depth discussion of the strengths and weaknesses of correspondence tests, see Riach and Rich (2002), Bertrand and Mullainathan (2004) and Pager (2007). For elaboration on the ethical aspects of this type of field experiments, see Riach and Rich (2004).

First, in line with the literature, we give no direct indication of the "heterosexual" candidate's sexual orientation. We follow Weichselbaumer (2013) arguing that "given that heterosexuality is one of main organising principles of Western societies and is considered 
as the norm to which people typically adhere to, employers are unlikely to infer any deviation from that norm unless a respective indication is provided". However, the "heterosexual" applicant in our experiment could also be a lesbian applicant not disclosing her sexual orientation. The "lesbian" candidates we compare to "heterosexual" candidates in our framework are therefore actually "openly lesbian" and the "heterosexual" candidates are actually candidates with an unrevealed sexual orientation. As a result, this comparison also includes the costs associated with disclosing lesbian orientation.

Second, our experiment's design can only demonstrate discrimination, if any, at the initial stage of the selection process. Because we simply measure call-back rates for first interviews, we cannot make any statements about discrimination in the later stages of the selection process, let alone in wages or opportunities for promotion. However, Bertrand and Mullainathan (2004) argue that lower interview rates are expected to translate into lower job offer rates and lower earnings. Moreover because job interviews are costly, firms invite candidates for an interview only if they have a reasonably high chance of getting the job.

It is important to keep in mind that we are especially interested in the heterogeneity of sexual orientation discrimination by age and motherhood. As the aforementioned limitations cause a similar shift in the measures of discrimination for all age and motherhood categories of women, our main research conclusions remain valid. It is more important to note that our research design does not enable us to identify the direct and independent empirical importance of the hiring penalty heterosexual women pay for getting, on average, more children and having more rearing responsibilities. On the one hand, both the revelation of younger age and the revelation of motherhood (especially at 
the younger age) in the fictitious job applications are positively related both to the probability of getting (more) children and to the amount of rearing responsibilities (in the near future). Therefore, if discrimination relatively favours lesbians when comparing heterosexual and lesbian candidates at the younger age and/or with a revealed child, this may indicate that both characteristics of lesbian women appeal to the employer. Moreover, there could also be another reason why the applicants' age may have an effect on unequal treatment. If experience acts, by analogy with education (see Section 2.4), as a screening device to reduce prejudice, this should lower unequal treatment at older ages because the number of years of work experience is higher. However, because the young job candidates have between three and seven years of work experience, one could expect that this is not an important driver for heterogeneity in discrimination.

\section{Results and Discussion}

Table 1 presents our main statistical results based on the experimental dataset. We follow the literature by providing two statistical measures: the net discrimination rate and the positive call-back ratio. Because two applications were sent to each vacancy, there are four possible outcomes: (i) positive call-back for neither candidate, (ii) positive call-back for both candidates, (iii) positive call-back only for the heterosexual candidate and (iv) positive callback only for the lesbian candidate. Overall, in 134 of the 576 vacancies, at least one candidate received a positive call-back. Twenty-eight cases resulted in a positive call-back 
for just the heterosexual candidate and 39 for the lesbian candidate only. The net discrimination rate is calculated by reducing the number of applications for which the heterosexual candidate was preferred by the number of applications for which the lesbian candidate was preferred. This difference is then divided by the number of applications for which at least one of them received a positive call-back. The result is a net measure of the number of discriminatory acts a minority applicant can expect to encounter per application. Overall, this net discrimination rate is -0.08 . Based on a standard $\chi^{2}$ test, we cannot reject the hypothesis that candidates of both sexual orientations were equally often treated (un)favourably.

The positive call-back ratio is obtained by dividing the percentage of applications for which heterosexual candidates received a positive call-back by the corresponding percentage for the lesbian candidates. The value for this statistic presented in Table 1 (Panel A) confirms the finding based on the net discrimination rate. Overall, the positive call-back rate is $0.16^{12}$ for heterosexual candidates and 0.18 for lesbian candidates. The resulting positive call-back ratio is 0.90 , indicating that the heterosexual candidates received $10 \%$ less invitations compared with their lesbian counterparts. This ratio is not significantly different from 1 . In conclusion, overall, both the net discrimination rate and the call-back ratio suggest statistically insignificant levels of unequal treatment (in favour) of lesbians in the occupations tested in the Belgian labour market. This result contrasts with the substantial magnitude of discrimination against lesbians in other European countries as highlighted in

\footnotetext{
${ }^{12} 0.16=(67+28) / 576$
} 
our introduction. Regression analysis leads to the same statistical conclusions because, by construction, the observable characteristics are equal for both the heterosexual and the lesbian candidates for each vacancy. ${ }^{13}$

\section{TABLE 1 ABOUT HERE}

If both statistical measures are broken down by the candidate's age (Table 1, Panel B), we see that both measures point in the direction of (weakly) significant evidence for positive discrimination towards lesbians at the younger age. In that case, the positive call-back ratio indicates that the heterosexual job candidates in our experiment had a $20 \%$ lower probability of getting invited for a job interview compared with their lesbian counterparts. At the age of 37, however, no unequal treatment at all is identified. These observations are in line with our theoretical expectations: discrimination is more in favour of the lesbian candidates at the age of 25 (compared with discrimination at the age of 37 ) because at that age heterosexual women are expected to pay the price for their higher probability of maternity relative to older women having, independently of their sexual orientation, a low probability of future fertility.

Analysing our research findings by the resume's revelation of a child (Table 1, Panel C) results, in line with our expectations, in a net discrimination rate and positive call-back ratio that are relatively more in favour of lesbian candidates who reveal their motherhood status.

\footnotetext{
${ }^{13}$ We also tested the robustness of our results adopting the econometric framework recently proposed by Neumark (2012) to correct for the potential bias introduced by (sexual orientation) group differences in the variance of unobservable job-relevant characteristics. This, however, led to the same conclusions.
} 
However, the heterogeneity along this dimension is not substantial and the discrimination measures are not significant for both categories in this split-up. Apparently, in the case of heterosexual women, the penalty for taking up more rearing tasks within the household than lesbian women is, on average, less severe than the penalty for having high(er) maternity probabilities at the younger age. Alternatively, because we compare women with one child to women without any indication with respect to motherhood, employers may be unsure about the number of children in the latter case.

Analysing the research observations by age and motherhood simultaneously (Table 1, Panel D) results in discrimination measures completely in line with our expectations. Positive discrimination towards lesbians is highest when testing with candidates who are young and indicate having a child. For this subgroup, the probability of being invited for a job interview is $25 \%$ less for heterosexual candidates than for lesbian candidates. Both measures are least favourable for lesbians (and essentially point at zero unequal treatment) when testing with older candidates who do not indicate any children. We obtain intermediate statistics for young candidates not indicating children or older candidates with a child. Based on the comparison of the measures for the latter two subgroups of candidates, younger age again seems to play a more important role in inducing positive discrimination towards lesbians than does the revelation of a child.

Table A-1 presents our secondary research results. First, we consider the net discrimination rate and the call-back ratio to the occupation level (Table $A-1$, Panel $B$ ). Doing so produces (only) a favourable treatment of an important magnitude for lesbian women in the occupation of manual worker, i.e. the low-skilled male-dominated occupation 
without customer contact. The fictitious lesbian candidates in our experiment received twice as many invitations to interview as their heterosexual counterparts when applying for this occupation. This finding seems to confirm that unequal treatment is higher among the low-educated and is more in favour of lesbians in male-dominated occupations and in occupations in which customer contact is not important. Indeed, if we aggregate the positive call-back ratio over the low-skilled and high-skilled occupations, we obtain a more favourable ratio for the former occupations (0.84) than for the latter occupations (0.95). Both ratios, however, are not significantly different from 1 . Furthermore, if we aggregate the positive call-back ratio over the occupations without and with customer contact, we obtain a ratio for the former occupations (0.84) that is more favourable for lesbian candidates than the ratio for the latter occupations (0.96). Analogously, if we aggregate the positive call-back ratio over the male-dominated and female-dominated occupations, we obtain ratios of 0.85 and 0.92 , respectively.

Second, we inspect whether discrimination differs by the gender of the contact person for the vacancy (Table A-1, Panel C). While we find no overall unequal treatment among female selection contacts, our results reveal that lesbian candidates are treated favourably if the contact person is male. This finding is consistent with that of Carlsson and Rooth (2007), providing evidence for higher levels of ethnic discrimination among male recruiters (compared with female recruiters) in Sweden. In addition, two "exotic" explanations for this evidence are found in the literature. On the one hand, female recruiters may be insecure about their own sexual orientation and therefore have a distaste for lesbian workers (Crow et al. 1998). On the other hand, male recruiters may be positively (sexually) agitated by 
lesbian candidates (Nyberg and Alston 1977; Crow et al. 1998). In a last exercise, for which the statistics are available upon request, we also analyse the observations by age and occupation and by age and gender of the recruiter on the other hand. Through this analysis, we find that the discrimination heterogeneity by age is more prevalent in those occupations other than manual worker and among female recruiters.

\section{Conclusion}

In this study, we reported the results of a field experiment designed to identify the effects of age and motherhood on discrimination based on the sexual orientation of women. We find that employers in Belgium discriminate against heterosexual women if these women are young and, to a lesser extent, if they have children. We find no unequal treatment at all at older ages. Our study results complement those by Petit (2007), finding that male job candidates are preferred over their female counterparts at young ages. In addition, we find that lesbians are somewhat more favourably treated in low-skilled occupations, occupations without customer contact and male-dominated occupations. This finding is driven by the high level of positive discrimination towards lesbians in the manual worker profession. Lastly, we find that female recruiters do not exercise unequal treatment, but male contact people treat lesbian job candidates favourably.

Although our experiment initially aimed at contributing to the literature on 
discrimination based on sexual orientation, the results mainly suggest that there is a penalty for young (heterosexual) women because of their high probability of maternity. Our findings tally with those of Gordo (2009), which indicate that women in Germany tend to consolidate their careers before motherhood to reduce career costs. From a policy perspective, these results suggest that rather than fighting discrimination against sexual minorities in the labour market, Belgian policies should aim at reducing the career penalty of motherhood. This should be done both by detecting and punishing discrimination against women in their fertile ages and by reducing the costs of maternity leave for firms.

Authorisation: The present research was reviewed and approved by the Ethical Affairs Committee of the Faculty of Economics and Business Administration of Ghent University.

Acknowledgements: We thank Jolien Sichien and Angelie Vancoillie for excellent research assistance. Furthermore, we are grateful to Bart Cockx, Eva Van Belle, Walter Van Trier and the seminar participants at Ghent University and Université catholique de Louvain for their insightful comments and suggestions, which have helped to improve this study considerably. The authors assume the sole scientific responsibility for the present work. 


\section{References}

Ahmed, A. M., L. Andersson, and M. Hammarstedt. 2011a. "Are gays and lesbians discriminated against in the hiring situation?" Institute for Labour Market Policy Evaluation Working Paper Series 21.

Ahmed, A. M., L. Andersson, and M. Hammarstedt. 2011b. "Inter- and intrahousehold earnings differentials among homosexual and heterosexual couples." British Journal of Industrial Relations 49(2): 258-278.

Albert, R., L. Escot, and J. A. Fernández-Cornejo. 2011. “A field experiment to study sex and age discrimination in the Madrid labour market." The International Journal of Human Resource Management 22(2): 351-375.

Antecol, H., and M. D. Steinberger. 2011. "Labour Supply differences between married heterosexual women and partnered lesbians: a semi-parametric decomposition approach." Economic Inquiry 51(1): 783-805.

Arabsheibani, G. R., A. Marin, and J. Wadsworth. 2005. "Gay's pay in the UK." Economica 72(286): 333-347.

Arrow, K. J. 1971. The Theory of Discrimination. Princeton: Princeton University Press.

Badgett, L.. 2006. “Discrimination based on sexual orientation: A review of the literature in economics and beyond," in William M. Rodgers III, eds. Handbook on the Economics of Discrimination. Cheltenham: Edward Elgar.

Baert, S., B. Cockx, N. Gheyle, and C. Vandamme. 2013. “Do Employers Discriminate Less 
if Vacancies are Difficult to Fill? Evidence from a Field Experiment." IZA Discussion Paper Series 7145.

Baumle, A. 2009. "The cost of parenthood: Unraveling the effects of sexual orientation and gender on income." Social Science Quarterly, 90(4): 983-1002.

Becker, G. 1957. The Economics of Discrimination. Chicago: University of Chicago Press.

Berg, N., and D. Lien. 2002. "Measuring the effect of sexual orientation on income: evidence of discrimination." Contemporary Economic Policy 20(4): 394-414.

Bertrand, M., and S. Mullainathan. 2004. "Are Emily and Greg more employable than Lakisha and Jamal? A field experiment on labor market discrimination." American Economic Review 94(4): 991-1013.

Black, D. A., H. R. Makar, S. G. Sanders, and L. J. Taylor. 2003. "The earnings effects of sexual orientation." Industrial and Labor Relations Review 56(3): 449-469.

Blandford, J. M. 2003. "The nexus of sexual orientation and gender in the determination of earnings." Industrial and Labor Relations Review 56(4): 622-642.

Bursell, M. 2007. "What's in a name? A field experiment test for the existence of ethnic discrimination in the hiring process." Stockholm University Linnaeus Center for Integration Studies Working Paper Series 7.

Carlsson, M., and D.-O. Rooth. 2007. "Evidence of ethnic discrimination in the Swedish labor market using experimental data." Labour Economics 14(4): 716-729.

Carpenter, C. S. 2005. "Self-reported sexual orientation and earnings: Evidence from California." Industrial and Labor Relations Review 58(2): 258-273. 
Clain, S. H., and K. Leppel. 2001. "An investigation into sexual orientation discrimination as an explanation for wage differences." Applied Economics 33(1): 37-47.

Crow, S. M., L. Y. Fok, and S. J. Hartman. 1998. "Who is at greatest risk of work-related discrimination: Women, blacks and homoseksuals?" Employee responsibilities and rights journal 11(1): 15-26.

Drydakis, N. 2011. "Women's Sexual Orientation and Labor Market Outcomes in Greece." Feminist Economics 17(1): 89-117.

Drydakis, N. Forthcoming. "Sexual Orientation Discrimination in the Cypriot Labour Market: Distastes or Uncertainty?" International Journal of Manpower.

Elmslie, B., and E. Tebaldi. 2007. "Sexual orientation and labor market discrimination." Journal of Labor Research 28(3): 436-453.

Eurobarometer. 2006. Public Opinion in the European Union. Standard Eurobarometer, Wave 66. Brussels: European Commission.

Goldin, C., and C. Rouse. 2000. "Orchestrating Impartiality: The Impact of "Blind" Auditions on Female Musicians." American Economic Review 90(4): 715-741.

Gordo, L. R. 2009. "Why Are Women Delaying Motherhood in Germany?" Feminist Economics 15(4): 57-75.

ILGA-Europe. 2013. Annual Review of the Human Rights Situation of Lesbian, Gay, Bisexual, Trans and Intersex People in Europe. Brussels: ILGA-Europe.

Jepsen, L. 2007. “Comparing the earnings of cohabiting lesbians, cohabiting heterosexual women, and married women: Evidence from the 2000 census." Industrial Relations 46(4): 
$699-727$.

Jobat. 2013. "Loon bepaalt naam van je kind." http://www.jobat.be/nl/artikels/loonbepaalt-naam-van-je-kind/ (accessed May 2013).

Leppel, K. 2009. “Labour Force Status and Sexual Orientation.” Economica 76(301): 197207.

Neumark, D. 1999. "Wage Differentials by Race and Sex: The Roles of Taste Discrimination and Labor Market Information." Industrial Relations 38(3): 414-445.

Neumark, D., R. J. Bank, and K. D. Van Nort. 1996. "Sex Discrimination in Restaurant Hiring: An Audit Study." Quarterly Journal of Economics 111(3): 915-941.

Neumark, D. 2012. "Detecting Discrimination in Audit and Correspondence Studies." Journal of Human Resources 47(4): 1128-1157.

Nyberg, K. L., and J. P. Alston. 1977. "Homosexual labeling by university youths." Adolescence 12(48): 541-546.

Pager, D. 2007. "The use of field experiments for studies of employment discrimination: contributions, critiques, and directions for the future." Annals of the American Academy of Political and Social Science 609(1): 104-133.

Patacchini, E., G. Ragusa, and Y. Zenou. 2012. “Unexplored dimensions of discrimination in Europe: Homosexuality and physical appearance." CEPR Working Papers 9179.

Petit, P. 2007. "The effects of age and family constraints on gender hiring discrimination: A field experiment in the French financial sector." Labour Economics 14(3): 371-391. 
Plug, E. and P. Berkhout. 2004. "Effects of sexual preferences on earnings in the Netherlands." Journal of Population Economics 17(1): 117-131.

Reiss, B. F., J. Safer, and W. Yotive. 1976. "Psychological Test Data on Female Homosexuality: A Review of the Literature." Journal of Homosexuality 1(1): 71-86.

Riach, P. A., and J. Rich. 2002. "Field Experiments of Discrimination in the Market Place." Economic Journal 112(483): 480-518.

Riach, P. A., and J. Rich. 2004. "Deceptive Field Experiments of Discrimination: Are They Ethical?" Kyklos 57(3): 457-470.

Riach, P. A., and J. Rich. 2006. “An Experimental Investigation of Sexual Discrimination in Hiring in the English Labor Market." The B.E. Journal of Economic Analysis \& Policy 6(2, Advances): 1-22.

Rooth, D.-O. 2009. “Obesity, Attractiveness, and Differential Treatment in Hiring: A Field Experiment." Journal of Human Resources 44(3): 710-735.

Taubman, P. J., and T. Wales. 1974. Higher Education and Earnings: College as an Investment and Screening Device. Massachusetts: NBER Books.

Theunissen, G., M. Verbruggen, A. Forrier, and L. Sels. 2009. “Career Sidestep, Wage Setback? The Impact of Different Types of Employment Interruptions on Wages." Gender, Work \& Organisation 18(1): 110-131.

Weichselbaumer, D. 2003. "Sexual orientation discrimination in hiring." Labour Economics 10(6): 629-642.

Weichselbaumer, D. 2004. "Is it Sex or Personality? The Impact of Sex-Stereotypes on 
Discrimination in Applicant Selection." Eastern Economic Journal 30(2): 159-186.

Weichselbaumer, D. 2013. "Testing for Discrimination against Lesbians of Different Marital Status: A Field Experiment." IZA Discussion Paper Series 7424. 
Appendix A: Additional Tables

TABLE A-1 ABOUT HERE 
Table 1 Main Research Results

\begin{tabular}{|c|c|c|c|c|c|c|c|c|c|}
\hline Observations & $\begin{array}{l}\text { Jobs } \\
\text { (No.) }\end{array}$ & $\begin{array}{c}\text { Neither } \\
\text { candidate } \\
\text { positive call- } \\
\text { back } \\
\text { (No.) }\end{array}$ & $\begin{array}{c}\text { Both } \\
\text { candidates } \\
\text { positive call- } \\
\text { back } \\
\text { (No.) }\end{array}$ & $\begin{array}{c}\text { Only } \\
\text { heterosexual } \\
\text { candidate } \\
\text { positive call- } \\
\text { back } \\
\text { (No.) }\end{array}$ & 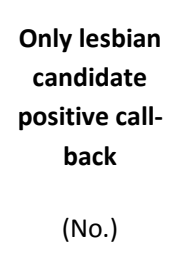 & $\begin{array}{c}\text { Net } \\
\text { discrimination } \\
\text { rate }\end{array}$ & $x^{2}$ & $\begin{array}{l}\text { Positive call- } \\
\text { back ratio }\end{array}$ & $\mathbf{t}$ \\
\hline \multicolumn{10}{|l|}{ A. All observations } \\
\hline All observations & 576 & 442 & 67 & 28 & 39 & -0.08 & 1.81 & 0.90 & 1.34 \\
\hline \multicolumn{10}{|c|}{ B. Heterogeneity by the candidate's age } \\
\hline 25 year & 288 & 220 & 31 & 13 & 24 & $-0.16^{*}$ & 3.27 & $0.80^{*}$ & 1.81 \\
\hline 37 year & 288 & 222 & 36 & 15 & 15 & 0.00 & 0.00 & 1.00 & 0.00 \\
\hline \multicolumn{10}{|c|}{ C. Heterogeneity by the candidate's motherhood } \\
\hline One child & 288 & 219 & 39 & 11 & 19 & -0.12 & 2.13 & 0.86 & 1.46 \\
\hline No children & 288 & 223 & 28 & 17 & 20 & -0.05 & 0.24 & 0.94 & 0.49 \\
\hline \multicolumn{10}{|c|}{ D. Heterogeneity by the candidate's age and motherhood } \\
\hline 25 year * one child & 144 & 112 & 17 & 4 & 11 & $-0.22 *$ & 3.27 & $0.75^{*}$ & 1.82 \\
\hline 25 year * no children & 144 & 108 & 14 & 9 & 13 & -0.11 & 0.73 & 0.85 & 0.85 \\
\hline 37 year * one child & 144 & 107 & 22 & 7 & 8 & -0.03 & 0.07 & 0.97 & 0.26 \\
\hline 37 year * no children & 144 & 115 & 14 & 8 & 7 & 0.03 & 0.07 & 1.05 & 0.26 \\
\hline
\end{tabular}

Note: The net discrimination rate is calculated by reducing the number of applications for which the heterosexual candidate was preferred by the number of applications for which the lesbian candidate was preferred and this difference is then divided by the number of application pairs in which at least one received a positive callback. The chi-square test for the net discrimination rate tests the null hypothesis that both candidates are treated unfavourably just as frequently. ${ }^{* * *}$ indicates significance at the $1 \%$ significance level, ${ }^{* *}$ at the $5 \%$ significance level and ${ }^{*}$ at the $10 \%$ significance level.

Note: The positive callback ratio is calculated by dividing the percentage of applications for which heterosexual candidates received a positive callback by the corresponding percentage for lesbian candidates. The $t-$ test for the positive callback ratio tests the null hypothesis that the probability of a positive answer is the same for candidates from both groups. As two applicants contacted the same firm, the probability of the heterosexual applicant receiving an invitation was correlated with the probability of the lesbian applicant receiving one. Therefore, standard errors are corrected for clustering of the observations at the vacancy level. $* * *$ indicates significance at the $1 \%$ significance level, $* *$ at the $5 \%$ significance level and * at the $10 \%$ significance level. 
Table A-1 Secondary Research Results

\begin{tabular}{|c|c|c|c|c|c|c|c|c|c|}
\hline Observations & $\begin{array}{l}\text { Jobs } \\
\text { (No.) }\end{array}$ & $\begin{array}{c}\text { Neither } \\
\text { candidate } \\
\text { positive call- } \\
\text { back } \\
\text { (No.) }\end{array}$ & $\begin{array}{c}\text { Both } \\
\text { candidates } \\
\text { positive call- } \\
\text { back } \\
\text { (No.) }\end{array}$ & $\begin{array}{c}\text { Only } \\
\text { heterosexual } \\
\text { candidate } \\
\text { positive call- } \\
\text { back } \\
\text { (No.) }\end{array}$ & 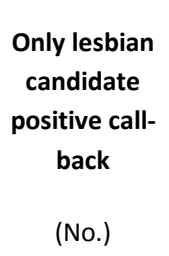 & $\begin{array}{c}\text { Net } \\
\text { discrimination } \\
\text { rate }\end{array}$ & $x^{2}$ & $\begin{array}{l}\text { Positive call- } \\
\text { back ratio }\end{array}$ & $\mathbf{t}$ \\
\hline \multicolumn{10}{|l|}{ A. All observations } \\
\hline All observations & 576 & 442 & 67 & 28 & 39 & -0.08 & 1.81 & 0.90 & 1.34 \\
\hline \multicolumn{10}{|c|}{ B. Heterogeneity by occupation } \\
\hline Secretary & 96 & 80 & 8 & 3 & 5 & -0.13 & 0.50 & 0.85 & 0.70 \\
\hline Nanny & 96 & 70 & 13 & 8 & 5 & 0.12 & 0.69 & 1.17 & 0.83 \\
\hline Manual worker & 96 & 75 & 6 & 3 & 12 & $-0.43^{* *}$ & 5.40 & $0.50^{* *}$ & 2.38 \\
\hline Management assistant & 96 & 83 & 7 & 2 & 4 & -0.15 & 0.67 & 0.82 & 0.81 \\
\hline Ergotherapist & 96 & 62 & 23 & 3 & 8 & -0.15 & 2.27 & 0.84 & 1.52 \\
\hline Engineer & 96 & 72 & 10 & 9 & 5 & 0.17 & 1.14 & 1.27 & 1.07 \\
\hline \multicolumn{10}{|c|}{ C. Heterogeneity by gender of the recruiter } \\
\hline Female recruiter & 313 & 239 & 39 & 16 & 19 & -0.04 & 0.26 & 0.95 & 0.51 \\
\hline Male recruiter & 215 & 166 & 21 & 9 & 19 & $-0.20 *$ & 3.57 & $0.75^{*}$ & 1.90 \\
\hline
\end{tabular}

Note: The net discrimination rate is calculated by reducing the number of applications for which the heterosexual candidate was preferred by the number of applications for which the lesbian candidate was preferred and this difference is then divided by the number of application pairs in which at least one received a positive call-back. The chi-square test for the net discrimination rate tests the null hypothesis that both candidates are treated unfavourably just as frequently. ${ }^{* * *}$ indicates significance at the $1 \%$ significance level, ${ }^{* *}$ at the $5 \%$ significance level and $*$ at the $10 \%$ significance level.

Note: The positive call-back ratio is calculated by dividing the percentage of applications for which heterosexual candidates received a positive call-back by the corresponding percentage for lesbian candidates. The $t-$ test for the positive call-back ratio tests the null hypothesis that the probability of a positive answer is the same for candidates from both groups. Standard errors are corrected for clustering of the observations at the vacancy level. ${ }^{* * *}$ indicates significance at the $1 \%$ significance level, ${ }^{* *}$ at the $5 \%$ significance level and ${ }^{*}$ at the $10 \%$ significance level.

Note: The number of jobs with a male or a female recruiter does not equal the total number of jobs as for some vacancies we could not identify the gender of the contact person. 